\title{
Standardised method of determining vibratory perception thresholds for diagnosis and screening in neurological investigation
}

\author{
J. M. G OLDBER G A N D U. LI N D B L O M
}

\author{
From the Department of Neurology, Huddinge University Hospital, Huddinge, Sweden
}

SUMMARY Vibration threshold determinations were made by means of an electromagnetic vibrator at three sites (carpal, tibial, and tarsal), which were primarily selected for examining patients with polyneuropathy. Because of the vast variation demonstrated for both vibrator output and tissue damping, the thresholds were expressed in terms of amplitude of stimulator movement measured by means of an accelerometer, instead of applied voltage which is commonly used. Statistical analysis revealed a higher power of discrimination for amplitude measurements at all three stimulus sites. Digital read-out gave the best statistical result and was also most practical. Reference values obtained from 110 healthy males, 10 to 74 years of age, were highly correlated with age for both upper and lower extremities. The variance of the vibration perception threshold was less than that of the disappearance threshold, and determination of the perception threshold alone may be sufficient in most cases.

The vibration "sense" has attracted considerable interest and its physiology has been studied extensively (see Calne and Pallis, 1966; Talbot et al., 1968). Yet we do not know its functional relevance for the normal life of animal or man. In clinical neurology, on the other hand, it has long been known that reduced or abolished ability to feel vibration is characteristic of certain diseases which affect primarily the spinal cord, such as subacute combined degeneration of the cord and multiple sclerosis (Egger, 1899; Rydel and Seiffer, 1903; Williamson, 1922). Vibration sensibility may also be affected by cerebral lesions, especially if subcortical (Fox and Klemperer, 1942).

Impairment of vibratory sensibility, starting distally in the limbs, may be an early sign of peripheral neuropathy (Williamson, 1922; Nielsen, 1971, 1972; Bergström et al., 1975), and measurements of perception thresholds can be used as an index of subclinical disease from metabolicnutritional disorders or environmental toxic agents, where the patients themselves are unaware of the defect. A well-known example is diabetic neuropathy (Collens et al., 1946 and others). Since vibra-

Address for reprint requests: Dr U. Lindblom, Department of Neurology, Huddinge University Hospital, S-14 186 Huddinge, Sweden.

Accepted 19 February 1979 tion sensation is mediated by the largest afferent nerve fibres, the vibration threshold reflects the functional integrity of these sensory fibres.

The clinical importance demands that vibration sensibility should be measured quantitatively. The frequency range (Rumpf, 1889) or the disappearance time of vibrations from a tuning fork (Treitel, 1897; Pearson, 1928) used by earlier observers have been supplemented by threshold determinations by means of electromagnetic devices (Knudsen, 1928; Geldard and Gilmer, 1934; Gregg, 1951; Cosh, 1953; Verrillo, 1966). The applied voltage is commonly used as a measure of sensitivity. This reflects the energy delivered to the tissue but not the displacement which is the adequate stimulus to the receptors (Hunt, 1961; Sato, 1961; Lindblom and Lund, 1966). Furthermore, there are several instrumental and other technical errors associated with electrical vibrators that affect vibration amplitude (Geldard and Gilmer, 1934; Gregg, 1951; Nielsen, 1975; Sherrick, 1975). A major factor is the variation in mechanical impedance and stiffness of the various tissues with consequent variations in the damping and spread of the vibration. The amplitude of the vibration also depends on the pressure with which the stimulator is applied (Cohen and Lindley, 1938). It would seem more logical and might lead to less variability if the stimulus were expressed in terms of 
actual stimulator movement. This reflects the tissue displacement (Lindblom and Lund, 1966; Verrillo, 1966) and may show a closer correspondence with the effective deformation of the receptors than the voltage applied to the vibrator. Using absolute measures will also be of basic importance when comparing different individuals and test sites, as well as measurements by different investigators.

The first aim of the present study was to compare vibration amplitude in terms of voltage applied to a vibrator with accelerometer-measured stimulator movement. The second aim was to develop and standardise a method for determination of vibratory sensation thresholds, to be used in both diagnostic and longitudinal neurological studies, and in screening of populations for neuropathies and other impairments of the nervous system. The study includes age-related reference values for selected stimulation sites.

\section{Subjects and methods}

We examined 110 healthy male volunteers, aged from 10 to 74 years (mean age 41.2 years, median age 41.9 years), of different occupations and socioeconomic status. A case history was taken on each person with special reference to states or diseases connected with neurological dysfunction. A clinical neurological examination was performed on all subjects by a trained neurologist as well as determination of motor conduction velocity of the median nerve. Subjects with signs or symptoms of neurological diseases, of the peripheral nervous system in particular, were excluded.

A Bio-Thesiometer (Bio-Medical Instruments Co, Newbury, Ohio, USA) producing a $100 \mathrm{~Hz}$ (twice the $\mathrm{AC}$ frequency) sine wave vibration was used for stimulation. The vertical movement of the stimulator head, a $13 \mathrm{~mm}$ diameter plastic probe with slightly rounded edges, was recorded by means of an accelerometer (Endevco 2221D) mounted on the moving shaft of the probe. The probe movement was actually in two planes with a proportional horizontal component, but only the vertical one was recorded in this study.

\section{VIBRATION AMPLITUDE MEASUREMENTS}

The arrangement used allows the vibration amplitude to be determined by three methods.

1. The applied voltage, which is monitored with the dial and read from the voltmeter of the BioThesiometer, can be converted to vibration amplitude in micrometres according to the formula $\mathrm{A}=\mathrm{V}^{2}$. $\mathrm{k}$. $(\mathrm{A}=$ amplitude; $\mathrm{V}=$ voltage; $\mathrm{k}=\mathrm{a}$ constant, dependent on vibrator characteristics). A calibration curve, made with a constant load against a standard resistance, is furnished by the manufacturer. The amplitude thus derived from the applied voltage will be labelled $A_{\text {bio. }}$.

2. The accelerometer output is amplified and derived twice to obtain a signal proportional to the ${ }_{0}$ movement. It is displayed on an oscilloscope, to check that a $100 \mathrm{~Hz}$ sinusoid vibratory stimulus is produced, and to allow measurement of the peak-to- $₹$ peak vibration amplitude in absolute units $=A_{\text {osc }}$.

3. The accelerometer signal is also fed to a digital voltmeter, parallel to the oscilloscope, calibrated for $\bar{O}$ direct reading of the peak-to-peak amplitude in 흠 micrometres $=\mathbf{A}_{\text {dig }}$.

Oscilloscope and digital voltmeter readings were $\mathbb{ه}$ calibrated in the range 30 to $100 \mu \mathrm{m}$ by measuring the movement of the stimulator probe with a light 2 microscope and a stroboscope. The manufacturer of. the accelerometer guarantees that extrapolation can $\overrightarrow{\vec{\omega}}$ be made from the calibration down to $0 \mu \mathrm{m}$ vibration $\stackrel{\omega}{\omega}$ amplitude.

With rice cushions supporting the examined site the stimulator was placed in a position as vertical $\vec{N}$ and at the same time as perpendicular as possible to 0 the skin and underlying bone. The instrument was $v$ applied to the skin with a pressure equal to its ow weight $(440 \mathrm{~g})$. Sometimes a slight extra pressurs 을 (about $50 \mathrm{~g}$ ) was added to provide good contact with $\overrightarrow{\mathrm{A}}$ the subcutaneous tissue and to prevent the prot $\mathbb{D}$ from sliding on the skin. Care was taken to apply the stimulator where the subcutaneous tissue was so the that the stimulus would be transferred maximal to the underlying bone. Stimulation was, for instance, not performed directly on tendons.

Three sites, relevant for examination of poly- $\Theta$ neuropathy, were selected for threshold determinations of vibratory sensitivity: tarsal-the dorsomedial aspect of the first metatarsal bone; tibial-the flat surface of the proximal part of the tibia; carpal-the dorsum of the metacarpal bone $\mathbb{D}$ of the index finger.

All measurements were carried out on the left side $\frac{\bar{O}}{3}$ of the body, unless there was a history of injury on that side. The tests were performed in quiet surroundings with the subject at ease in a supine position on an examination bench. The same apparatus was used throughout the whole study and all threshold determinations were carried out by the $\frac{5}{3}$ same examiner.

VIBRATION THRESHOLD DETERMINATION

The vibration threshold was determined by the 윽 method of limits-that is, increasing the stimulus $D$ strength from zero to the point where vibratory sensation is first perceived (vibration perception $N$ threshold, VPT), and then decreasing the stimulus strength from a slightly supraliminal level to the

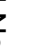


point where the sensation disappeared (vibration disappearance threshold, VDT). The average of VPT and VDT is taken as the vibration threshold (VT).

After a few trials, to acquaint the subject with the test procedure and to locate the general threshold level, three consecutive determinations were made on each test site. The procedure took about 10 minutes for each subject. All threshold values listed are the means of three determinations.

\section{Results}

VIBRATION AMPLITUDE AS A FUNCTION OF THE APPLIED VOLTAGE VERSUS ACTUAL STIMULATOR MOVEMENT

Tissue damping in general

Different tissues have different damping effects on the vibrator as illustrated in Fig. 1. The vibrator was fed with a fixed voltage (20V). In Fig. 1A the stimulator probe was allowed to vibrate freely in air, giving a peak-to-peak amplitude of $30 \mu \mathrm{m}$, as measured by means of the accelerometer $\left(\mathrm{A}_{\mathrm{osc}}\right)$. In Fig. 1B the vibrator was applied to metatarsal bone. The amplitude as read by the dial setting of the BioThesiometer ( $\mathrm{A}_{\text {bio }}$ ) was the same as in Fig. 1A but, as seen, the actual amplitude, as determined by the accelerometer (Aosc) was much reduced. The decrease in amplitude was still greater when the
A
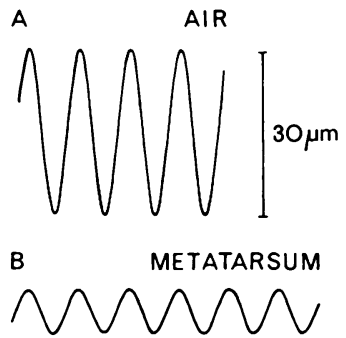
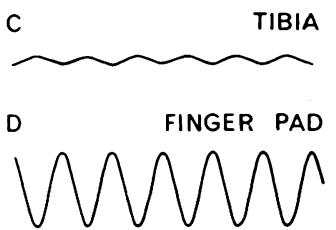

E

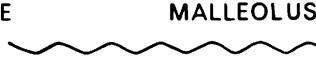

Fig. 1 Records from accelerometer when the vibrator is fed with constant voltage $(20 \mathrm{~V})$ and vibrates freely in air $(A)$, and in different tissues $(B-E)$. Vibration frequency $100 \mathrm{~Hz}$.

stimulator was applied to a solid mass such as the tibia (Fig. 1C). Figures 1D and E show the damping at some other commonly tested sites. The recordings in Fig. 1 demonstrate that the vibration amplitude cannot be derived from the voltage unless calibrated specifically for each stimulation site. A further observation from these measurements was that the sinusoidal stimulus was well retained in all relatively soft tissues. A slight distortion towards a triangular form could be seen when the stimulator was applied on bony masses (Figs. 1C and E).
Interindividual variations in tissue damping

Apart from differences in the damping effect between various tissues, there are also differences at the same site between subjects, which is illustrated in Fig. 2 . The stimulator was applied to the same sites (tibia and metatarsum, respectively) on 11 subjects, with four preset dial settings, $10,20,30$, and 40 volts corresponding to $1,4,9$, and $16 \mu \mathrm{m}$ respectively according to the manufacturer's calibration (Abio, on the abscissa). The actual amplitudes in absolute units $\left(\mathrm{A}_{\mathrm{osc}}\right)$ for the various dial settings are shown on the ordinate. Shaded areas indicate the variations (mean \pm 2 SD) of the actual vibration amplitudes. Both the amplitude magnitudes and the slopes were different for tibial and tarsal stimulation. For the same dial setting, the ratio between the actual amplitude means was approximately 0.25 . The standard deviations were found to be around $\pm 25 \%$ of the mean at both sites. Hence this tibial/tarsal ratio can vary considerably from person to person, with a ten-fold difference in extreme cases. Consequently, even if the Bio-Thesiometer were cali-

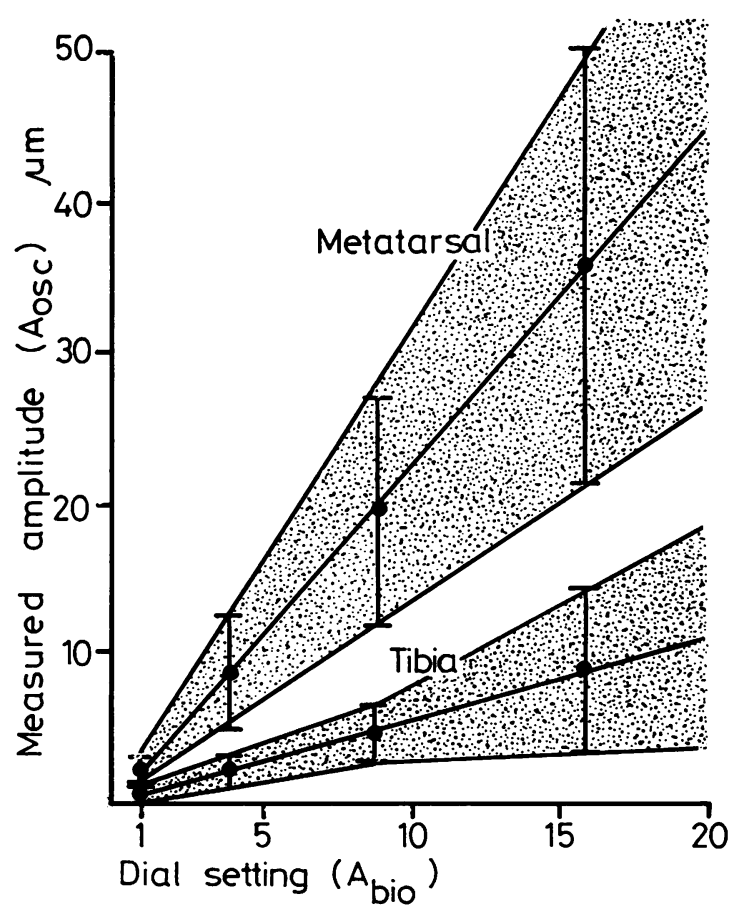

Fig. 2 Relationship between the dial setting of the Bio-Thesiometer and the measured movement amplitude of the stimulator in micrometres peak-to-peak, on metatarsal and tibial stimulation. Shaded areas indicate the variations (mean $\pm 2 S D$ ) of the movement amplitude at various settings. 
brated for different stimulation sites, an interindividual source of variation must still be considered.

Another type of relationship between the dial setting $\left(A_{b i o}\right)$ and actual stimulator movement (Adig) can be observed from vibration threshold determinations (VT) that were carried out on 54 consecutive subjects. The rectilinear regressions for three stimulation sites (tarsal, tibial, and carpal) are given in Table 1. It would be expected that the regression lines would go through the origin; hence when the amplitude is zero, the dial setting should be zero. However, none of the three regression lines went through the origin ( $y$ intercept $=a \neq 0$ ), which is confirmed by a $t$ test $(\mathrm{P}<0.001)$. The actual values point to a curved relationship between the dial setting $\left(\mathrm{A}_{\mathrm{bio}}\right)$ and the actual stimulator movement (Adig). This indicates that a certain amount of inertia must be overcome by the driving power of the vibrator. Thus, tissue damping effects on the resulting vibration are not constant but vary with the voltage applied to the vibrator as well as with different tissues. From Table 1, comparison can also be made of the different ratios for threshold means between dial setting $\left(\mathrm{A}_{\mathrm{bio}}\right)$ and actual stimulator movement at different stimulation sites. The tibial had the greatest damping effect and the carpal the least, judging from the separate means.

\section{Reproducibility}

A comparison of the reproducibility of voltage $\left(\mathrm{A}_{\text {bio }}\right)$ and amplitude (Adig) measurement of the vibratory stimulus for threshold determination (VT) has been made, and the analysis of variance is reproduced in Table 2 .

The formulae used for computation are as follows:

$\mathbf{F}=\frac{\mathbf{M S}_{\mathbf{b}}}{\mathbf{M S}_{\mathbf{w}}} \quad$ variance ratio

$F_{\mathrm{w}}=\frac{\mathbf{M S}_{\mathrm{w}_{1}}}{\mathbf{M S}_{\mathrm{w}_{2}}} \begin{aligned} & \text { (larger mean square) } \\ & \text { (lesser mean square) }\end{aligned}$ for equal means
$\mathrm{F}_{\mathrm{b}}=\frac{\mathrm{MS}_{\mathrm{b}_{1}}}{\mathrm{MS}_{\mathrm{b}_{2}}}$

$\mathrm{S}_{\mathrm{b}} \%=\sqrt{\frac{\overline{\mathrm{MS}_{\mathrm{b}}-\mathrm{MS}_{\mathrm{w}}}}{\mathrm{n}}} \cdot 100$

$F_{b \neq}=\left(\frac{S_{b} \%}{S_{b} \%}\right)^{2}$ for unequal means between

$\mathrm{S}_{\mathrm{w}} \%=\frac{\sqrt{\mathrm{MS}_{\mathrm{w}}}}{\overline{\mathrm{X}}} \cdot 100$

$F_{w \neq}=\left(\frac{S_{w_{1}} \%_{1}}{S_{w_{1}} \%_{2}}\right)^{2}$ for unequal means within

$\mathbf{F}=$ variance ratio (power of discrimination), $\mathbf{M S}_{\mathrm{b}}=$ mean square between classes (interindividual variation), $\mathbf{M S}_{\mathbf{w}}=$ mean square within classes (intraindividual variation), $F_{w}=$ test for equality of variances within classes, $F_{b}=$ test for equality between classes. $\mathrm{S} \%=$ variability around the mean.

The variance ratio $(F)$ is actually the interindividual variance compared to the intraindividual, which can be taken as a measure of the power of discrimination. At all three sites $F$ was highly significant $(\mathrm{P}<0.001)$ for both voltage $\left(\mathrm{A}_{\mathrm{bio}}\right)$ and amplitude (Adig) determinations. Furthermore, was constantly higher for the latter. The variation between classes (interindividual variation, $F_{b}$ ) was also significantly higher for amplitude measurements $\left(\mathrm{A}_{\text {dig }}\right)$ at all the three sites (tarsal, $\mathrm{P}<0.01$; tibiab $\mathrm{P}<0.05$; carpal, $\mathrm{P}<0.01$ ).

The intraindividual variation $\left(\mathrm{F}_{\mathrm{w}}\right)$ at the different sites did not exhibit the same constant trend on comparing the two methods for measurement of stimulator movement. At tarsal stimulation the intraindividual variation for amplitude measurement was lower than for voltage measurement $(P<0.025)$, at the tibial site it was equal, while with the carpal stimulation it was significantly greater $(P<0.01)$. The latter discrepancy may be explained by the fact that the Bio-Thesiometer is quite insensitive at low thresholds (cf Table 1) as shown by

Table 1 Regression analysis for three stimulation sites

\begin{tabular}{|c|c|c|c|c|c|c|c|}
\hline $\begin{array}{l}\text { Stimulation } \\
\text { site }\end{array}$ & $N$ & $\begin{array}{l}A_{d i g} \\
\bar{x} \pm e_{\bar{x}}\end{array}$ & $\begin{array}{l}A_{b i o} \\
\bar{y} \pm e_{\bar{y}}\end{array}$ & $\boldsymbol{b}$ & $a \pm e_{a}$ & $r$ & $t_{r}$ \\
\hline Tarsal & 54 & $1.828 \pm 0.433$ & $3.208 \pm 0.541$ & 1.188 & $\begin{array}{l}1.036 \pm 0.194 \\
t_{a}=5.33\end{array}$ & 0.951 & 22.3 \\
\hline Tibial & 54 & $0.883 \pm 0.091$ & $3.940 \pm 0.323$ & 3.313 & $\begin{array}{l}1.015 \pm 0.192 \\
t_{\mathrm{a}}=5.28\end{array}$ & 0.935 & 19.0 \\
\hline Carpal & 54 & $0.307 \pm 0.029$ & $0.451 \pm 0.030$ & 0.885 & $\begin{array}{l}0.179 \pm 0.025 \\
t_{a}=7.05\end{array}$ & 0.875 & 13.0 \\
\hline
\end{tabular}

$\overline{\mathrm{x}}=$ mean vibration threshold (VT), measured as actual stimulator movement (Adg); $\bar{y}=$ mean vibration threshold (VT) as measured by the Bio-Thesiometer $\left(A_{b 10}\right) ; b=$ regression coefficient; $a=y$-intercept; $r=$ correlation coefficient $; e_{\bar{x}}, e_{\bar{y}}=$ standard error of the mean; $e_{a}=e s t i m a t e$ of ${ }^{\prime}$ the standard deviation of $a$.

$t$ test for significance: the upper $0.1 \%$ point of the $t$ distribution with 50 degrees of freedom is 3.50 . 
Table 2 Analysis of variance

\begin{tabular}{|c|c|c|c|c|c|c|c|}
\hline & & & $\overline{\boldsymbol{x}}$ & $d f$ & & $M S$ & $S \%$ \\
\hline \multirow[t]{5}{*}{ Tarsal } & \multicolumn{2}{|l|}{ Between } & & 53 & \multirow{2}{*}{$F=24.2$} & 47.3603 & $121-$ \\
\hline & \multirow[t]{2}{*}{ Within } & $\mathbf{A}_{\mathrm{blo}}$ & 3.21 & 108 & & 1.9610 & -43.7 \\
\hline & & & & & & $\mathrm{F}_{\mathrm{w}+}=1.53^{*}$ & $F_{b+}=2.04^{* *}$ \\
\hline & Between & & 102 & 53 & \multirow{2}{*}{$F=73.2$} & 30.3967 & $173 \longrightarrow$ \\
\hline & Within & $\mathbf{A}_{\text {d1z }}$ & 1.83 & 108 & & 0.4150 & -35.2 \\
\hline \multirow[t]{5}{*}{ Tibial } & Between & & & 53 & \multirow{2}{*}{$F=16.1$} & 16.8915 & $58.3 \longrightarrow$ \\
\hline & \multirow[t]{2}{*}{ Within } & A blo & 3.94 & 108 & & 1.0520 & 26.0 \\
\hline & & & & & & & $F_{b+}=1.61^{*}$ \\
\hline & Between & & & 53 & \multirow{2}{*}{$\mathbf{F}=\mathbf{2 1 . 0}$} & 1.3461 & 74.0 \\
\hline & Within & $\mathbf{A}_{\text {dig }}$ & 0.88 & 108 & & 0.06395 & 28.6 \\
\hline \multirow[t]{5}{*}{ Carpal } & Between & & & 53 & \multirow{2}{*}{$F=25.8$} & 0.1431 & $47.5 \longrightarrow$ \\
\hline & \multirow[t]{2}{*}{ Within } & Ablo & 0.45 & 108 & & 0.00554 & -16.5 \\
\hline & & & & & & $F_{\mathrm{w} *}=1.64^{* *}$ & $F_{b *}=2.13^{* *}$ \\
\hline & \multirow{2}{*}{$\begin{array}{l}\text { Between } \\
\text { Within }\end{array}$} & & & 53 & \multirow{2}{*}{$F=33.2$} & 0.1397 & 69.3 \\
\hline & & $\mathbf{A}_{\mathrm{d} 1 \mathrm{~g}}$ & 0.31 & 108 & & 0.00421 & -21.1 \\
\hline
\end{tabular}

$\overline{\mathbf{x}}=$ mean vibration threshold $(V T)$ by voltage reading $\left(A_{b 10}\right)$ or digital reading $\left(A_{\text {dig }}\right)$ respectively; $d f=$ degrees of freedom; $M$ S $=$ mean square of variance; $F=$ ratio between mean squares-test for significance-for formulae, see text.

$\bullet=\mathrm{P}<0.05, * *=\mathrm{P}<0.01$.

Table 3 Analysis of variance

\begin{tabular}{|c|c|c|c|c|c|c|c|}
\hline & & & $\bar{x}$ & $d f$ & & $M S$ & $S \%$ \\
\hline \multirow[t]{5}{*}{ Tarsal } & \multicolumn{2}{|l|}{ Between } & \multirow[b]{2}{*}{2.15} & 66 & \multirow[b]{2}{*}{$F=119$} & 51.7453 & 192 \\
\hline & \multirow[t]{2}{*}{ Within } & Aosc & & 134 & & 0.4348 & $30.7 \square$ \\
\hline & & & & & & & $\mathrm{F}_{\mathrm{w} *}=2.47^{* * *}$ \\
\hline & Between & & & 66 & & 30.7875 & 167 \\
\hline & Within & $\mathbf{A}_{\mathrm{d1z}}$ & 1.91 & 134 & $F=221$ & 0.1391 & $19.5 \square$ \\
\hline \multirow[t]{4}{*}{ Tibial } & Between & & & 66 & \multirow{2}{*}{$F=116$} & 5.2521 & 126 \\
\hline & Within & Aosc & 1.04 & 134 & & 0.0453 & 20.4 \\
\hline & Between & & & 66 & \multirow[b]{2}{*}{$F=81.8$} & 3.9491 & 117 \\
\hline & Within & Adar & 0.97 & & & 0.04828 & 22.6 \\
\hline \multirow[t]{4}{*}{ Carpal } & Between & & & 66 & \multirow{2}{*}{$\mathbf{F}=\mathbf{2 0 . 7}$} & 0.1796 & 72.2 \\
\hline & Within & Aosc & 0.33 & 134 & & 0.00868 & 28.2 \\
\hline & Between & & & 66 & \multirow{2}{*}{$F=16.3$} & 0.1210 & 68.0 \\
\hline & Within & $\mathbf{A}_{\text {dis }}$ & 0.29 & 134 & & 0.00743 & 30.1 \\
\hline
\end{tabular}

$\overline{\bar{x}}=$ mean vibration threshold $(V T)$ by oscilloscope reading $\left(A_{\text {osc }}\right)$ or digital reading $\left(A_{d i g}\right)$ respectively; $d f=$ degrees of freedom; $M S=$ mean square of variance; $F=$ ratio between mean squares-test for significance-for formulae, see text.

$* * *=\mathrm{P}<0.001$. 
the curved relationship discussed in the preceding paragraph. Furthermore, the Bio-Thesiometer scale is usually read in "half-volts," which implies a decreased variability at low amplitudes.

\section{Technical sources of variation}

A comparison of the actual stimulator movements $\left(\mathrm{A}_{\mathrm{osc}}\right)$ from two different Bio-Thesiometers (denoted $X$ and $Y$ respectively) is illustrated in Fig. 3. At four different preset dial settings $(1,4,9$, and $16 \mu \mathrm{m}$, $\left.A_{b i o}\right)$ the vibrators were either allowed to vibrate freely in air or placed on the dorsomedial aspect of the first metatarsal bone (tarsal). As is seen, both in air and on tarsal stimulation, Bio-Thesiometer $\mathrm{X}$ gave a twofold higher resulting amplitude $\left(\mathrm{A}_{\text {osc }}\right)$ than did $Y$, although they both had the same dial setting. The discrepancies are likely to be the result of variations in mass and electrical characteristics of the vibrators and thus add a systematic source of error to the resulting amplitude.

The necessity for a technique that measures the actual displacement amplitude is obvious when summarising the vast sources of errors connected with measurement of the stimulus in terms of voltage applied to an electromagnetic vibrator. These errors consist of different damping effects in different tissues and subjects, and lack of true rectilinear relationships between voltage and actual displacement amplitude, as well as instrumental discrepancies.

\section{MEASUREMENT OF THE ACTUAL STIMULATOR MOVEMENT FOR DETERMINATION OF VIBRATORY SENSATION THRESHOLDS \\ Oscilloscope reading versus digital reading}

Vibratory sensation thresholds were determined for 67 subjects in order to compare the variability of oscilloscope readings ( $\mathrm{A}_{\mathrm{osc}}$ ) to that of digital readings (Adig). Three consecutive threshold determinations were carried out by the method of limits on three sites - tarsal, tibial, and carpal. The overall means, mean square, and variation around the mean are listed in Table 3. For tarsal stimulation, the intraindividual variation of the three consecutive threshold determinations was significantly smaller $(\mathrm{P}<0.001)$ for digital reading than for oscilloscope reading as computed by means of $F_{w}$. At this test site, digital reading seemed to have a higher power of discrimination $(F)$, in the sense that it differentiated better between individuals $\left(F_{\text {dig }} \gg F_{\text {osc }}\right)$. For tibial and carpal stimulation there were no significant differences in variation between the two methods of vibration amplitude measurement.

Measurement with an oscilloscope may have certain disadvantages in clinical work. The oscilloscope reading is time-consuming and requires the

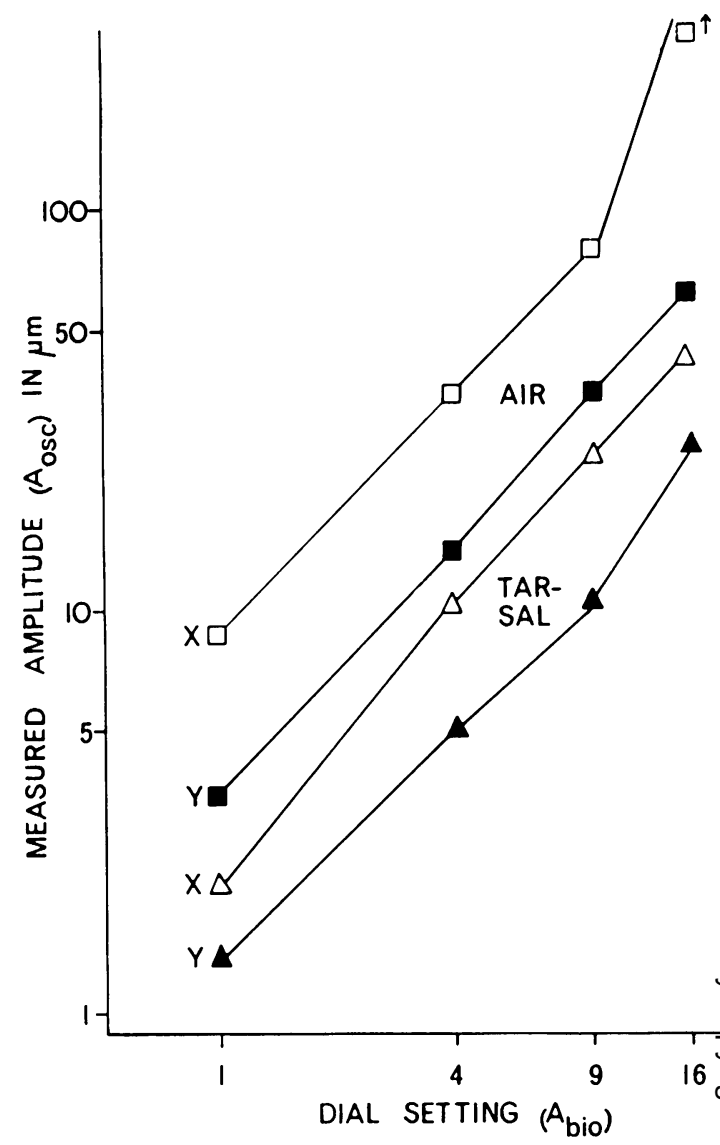

Fig. 3 Comparison of two different Bio-Thesiometers, $X$ and $Y$ : relationship between preset dial setting $(1,4,9$, and $16 \mu \mathrm{m})$, and actual amplitude from $X$ and $Y$ respectively, in air and on metatarsal stimulation on the same person.

assistance of extra personnel. The oscilloscope picture can be very coarse at low amplitudes because of the noise. As a consequence of these practical implications, and of the analysis of variance, the digital reading method is to be preferred to oscilloscope measurements.

\section{Variation among threshold means}

To minimise the effect of varying reaction times of examiner and subject tested, the average of the vibration perception threshold (VPT) and vibration disappearance threshold (VDT) is often used as the vibration threshold (VT). However, VDT is generally less distinct and the subject may occasionally find it difficult to determine when the vibratory sensation has disappeared. Hence, it would simplify 


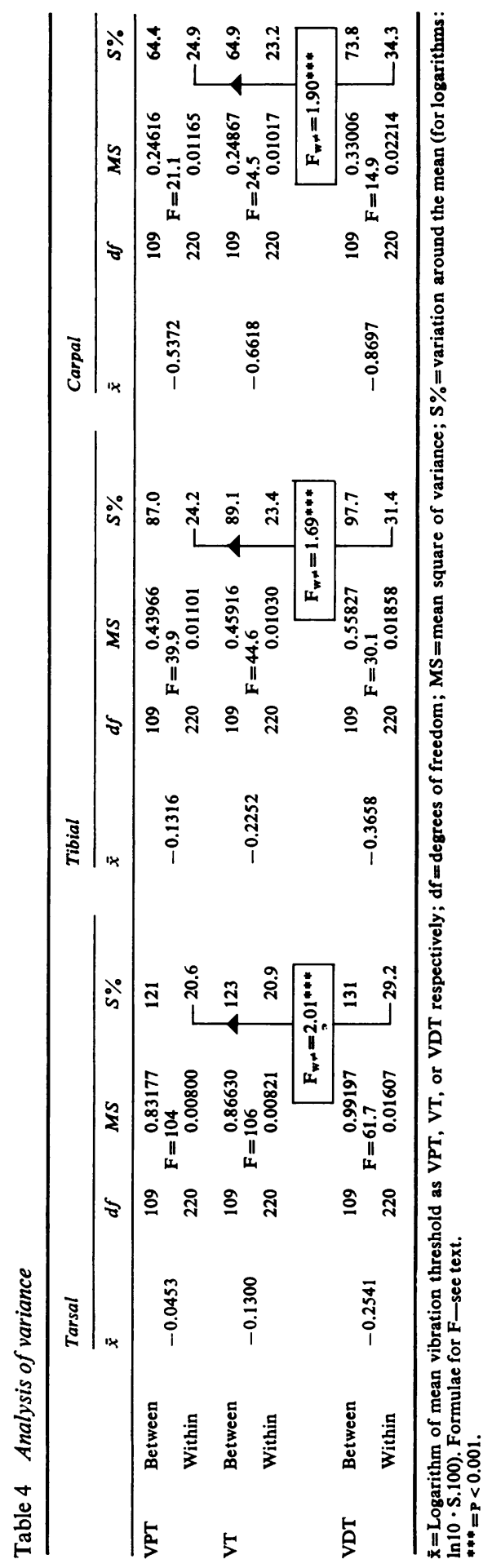


and shorten the procedure of vibration threshold measurement if only VPT were measured. Vibration thresholds were determined in 110 persons by the method of limits on the three sites-tarsal, tibial, and carpal. Both VPT, VDT, and VT display a skew distribution with a vast range. At tarsal stimulation, for example, there may be a hundred-fold difference between the thresholds of two people. An analysis of variance was carried out to ascertain the interindividual variation of the thresholds, as well as the intraindividual variation - that is, between the three consecutive determinations of either VPT, VT, or VDT. This variation equals the reproducibility of the three types of threshold. The thresholds were transformed to logarithms, being approximately normally distributed, in order to minimise the skew distribution (Table 4). At all three sites the "within" variation-that is, variability between three consecutive threshold determinations-was significantly smaller for VPT than for VDT $(P<0.001)$. The variation of VT did not differ significantly from that of VPT. The variation around the means, based on triple determinations, was in the range of $10-15 \%$.

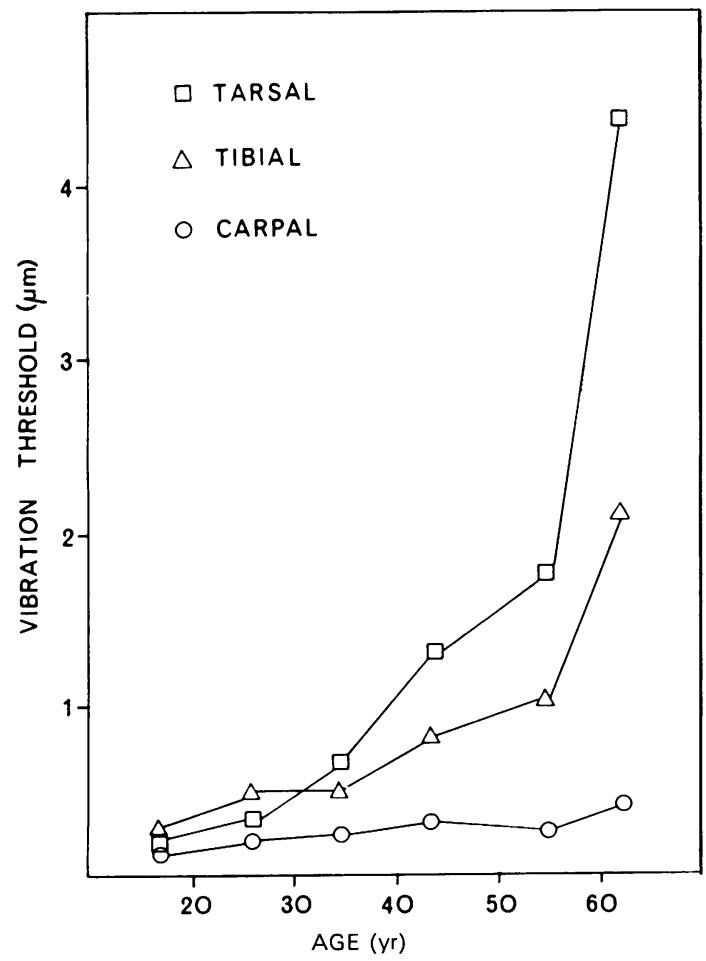

Fig. 4 Age-relation of vibration threshold, in means of $V T$ of various age groups, for stimulation at the three standard sites. For actual means, see Table 5.
Nielsen (1975) reports an intraindividual variation of $3 \%$ from double determinations as well as from measurement on different occasions, although his figures show a variability of $15-20 \%$.

The intraindividual variation has also been compared with the interindividual variation by means of the variance ratio, $F$, in Table 4. At all three measuring sites, the interindividual variation far exceeded the intraindividual variation for VPT, VDT, and VT $(\mathrm{P}<0.001)$. The discrimination power was significantly stronger for VPT compared to VDT at all three sites.

In spite of the greater variability of VDT than of VPT, the coherence of the three thresholds is indisputable. The correlation coefficients ( $\mathrm{rVPT} /$ VDT) for tarsal, tibial, and carpal thresholds were $0.979,0.948$, and 0.895 respectively. For ${ }^{\mathrm{rVPT}} / \mathrm{VT}$ they were somewhat higher, $0.996,0.991$, and 0.986 respectively. These correlations coefficients thus showed the same trends as did the analysis of variance.

The threshold gap (VPT-VDT) tends to be constant for each stimulus site in terms of the ratio VPT/VDT. The ratio is around 1.5 for tarsal and tibial stimulation, and about 2.0 for carpal stimulation (cf Lindblom and Lindström, 1976).

\section{Age and vibration thresholds}

The effect of age on vibration thresholds (VT) at the three stimulation sites is shown in Fig. 4 and Table 5. With increasing age the vibration threshold in creased and this was more prominent the morec distal was the stimulation site. The variability among? threshold means also tended to increase with age.

In the second decade the tarsal thresholds almost equalled the carpal (around $0.15-0.20 \mu \mathrm{m}$ ), but in the seventh decade there was a more than ten-fold difference $(5 \mu \mathrm{m}$ versus $0.38 \mu \mathrm{m})$, indicating a distally starting "age neuropathy". In the younger age groups tibial thresholds were higher than tarsal, but after the age of 30 years the opposite was the case.

By logarithmic transformation of the vibration threshold amplitudes (plotted on the ordinate

Table 5 Effect of age on vibration thresholds

\begin{tabular}{|c|c|c|c|c|c|}
\hline \multirow{2}{*}{$\begin{array}{l}\text { Age } \\
(y r)\end{array}$} & \multirow[t]{2}{*}{$N$} & \multirow[t]{2}{*}{$\bar{x}$} & Tarsal & \multirow{2}{*}{$\frac{\text { Tibial }}{\overline{\boldsymbol{y}} \pm e_{\bar{y}}}$} & \multirow{2}{*}{$\frac{\text { Carpal }}{\bar{y} \pm e_{\bar{y}}}$} \\
\hline & & & $\vec{y} \pm e_{\bar{y}}$ & & \\
\hline $\begin{array}{l}10-19 \\
20-29 \\
30-39 \\
40-49 \\
50-59 \\
60-74\end{array}$ & $\begin{array}{l}14 \\
16 \\
20 \\
20 \\
20 \\
20\end{array}$ & $\begin{array}{l}16.3 \\
25.4 \\
34.3 \\
43.2 \\
54.4 \\
62.8\end{array}$ & $\begin{array}{l}0.19 \pm 0.02 \\
0.35 \pm 0.07 \\
0.68 \pm 0.12 \\
1.32 \pm 0.26 \\
1.78 \pm 0.32 \\
5.18 \pm 1.14\end{array}$ & $\begin{array}{l}0.28 \pm 0.04 \\
0.49 \pm 0.09 \\
0.50 \pm 0.07 \\
0.81 \pm 0.10 \\
1.03 \pm 0.13 \\
1.75 \pm 0.39\end{array}$ & $\begin{array}{l}0.15 \pm 0.02 \\
0.20 \pm 0.02 \\
0.23 \pm 0.02 \\
0.32 \pm 0.03 \\
0.27 \pm 0.03 \\
0.38 \pm 0.09\end{array}$ \\
\hline
\end{tabular}

$\overline{\mathrm{x}}=$ mean age $; \overline{\mathrm{y}}=$ mean vibration threshold $(\mathrm{VT}) ; \mathrm{e}_{\overline{\mathrm{y}}}=$ standard error of the mean value of $y$. 
Table 6 Regression analysis: age and log vibration threshold (VT)

\begin{tabular}{|c|c|c|c|c|c|c|c|c|}
\hline Site & $N$ & $\bar{x}+e \bar{x}$ & $\bar{y}+\epsilon \bar{y}$ & $b$ & $a$ & $s_{y x}$ & $r$ & $t_{r}^{* * *}$ \\
\hline $\begin{array}{l}\text { Tarsal } \\
\text { Tibial } \\
\text { Carpal }\end{array}$ & $\begin{array}{l}110 \\
110 \\
110\end{array}$ & $\begin{array}{l}41.15 \pm 1.51 \\
41.15 \pm 1.51 \\
41.15 \pm 1.51\end{array}$ & $\begin{array}{l}-0.1239 \pm 0.05 \\
-0.2177 \pm 0.04 \\
-0.6541 \pm 0.03\end{array}$ & $\begin{array}{l}0.026 \\
0.015 \\
0.0068\end{array}$ & $\begin{array}{l}-1.2035 \\
-0.8386 \\
-0.9334\end{array}$ & $\begin{array}{l}0.344 \\
0.309 \\
0.266\end{array}$ & $\begin{array}{l}0.771 \\
0.614 \\
0.375\end{array}$ & $\begin{array}{l}12.58 \\
8.08 \\
4.21\end{array}$ \\
\hline Carpal linear & 110 & $41.15 \pm 1.51$ & $0.275 \pm 0.02$ & 0.0052 & 0.059 & 0.191 & 0.400 & 4.54 \\
\hline
\end{tabular}

$\overline{\mathrm{x}}=$ age, $\overline{\mathrm{y}}=$ logarithm of vibration threshold (VT), $\mathrm{b}=$ regression coefficient, $\mathrm{a}=\mathrm{y}$-intercept, $\mathrm{s}_{\mathrm{yx}}=\mathrm{estimate}$ of residual variation, $\mathrm{r}=$ correlation coefficient, $e_{\bar{x}}=$ standard error of the mean value of $x$.

****The upper $0.1 \%$ point of the $t$ distribution with 100 degrees of freedom is 3.39

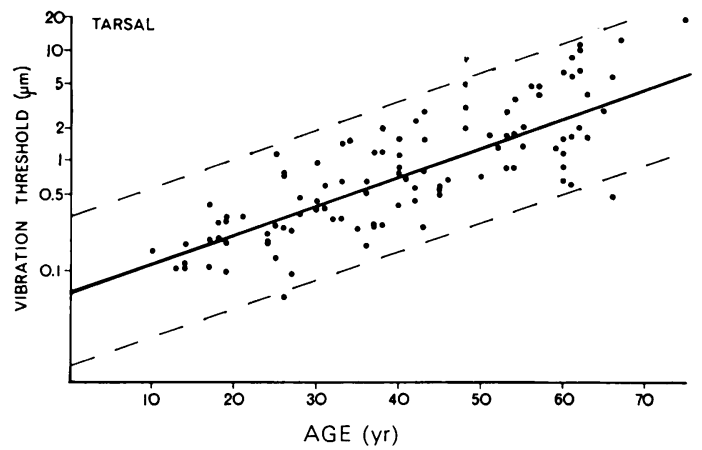

(a)

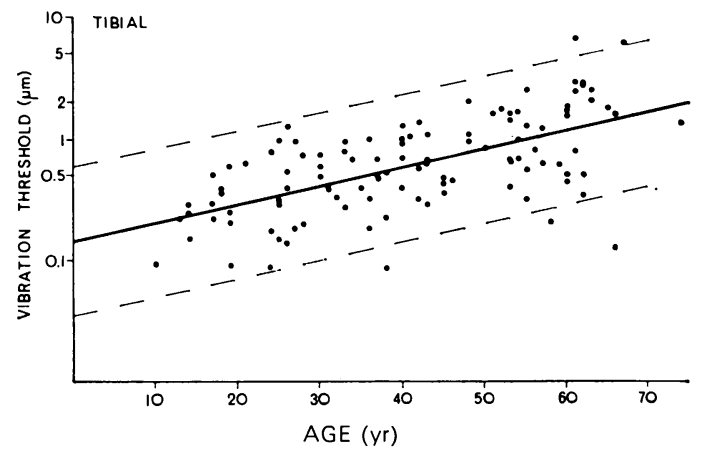

(b)

Fig. 5 Age-relation of vibration thresholds $(V T)$, for metatarsal (a) and tibial (b) stimulation. Logarithmic scale on ordinates. Hatched lines mark $\pm 2 S_{y x}$ around the mean. For regressions, see Table 6.

against age in absolute terms on the abscissa), a rectilinear regression was achieved; this semilogarithmic plot is shown for tarsal and tibial thresholds in Fig. 5 and Table 6. From the regressions we found that tarsal thresholds increased $6.2 \%$ per year ( $=83 \%$ in 10 years), tibial $3.4 \%$ per year $(=43 \%$ in 10 years $)$, and carpal $1.5 \%$ per year ( $=16 \%$ in 10 years). For carpal thresholds, however, a plot in absolute terms gave a slightly better fit to a rectilinear regression in terms of $r$. Thus, carpal thresholds showed a constant increase of $0.005 \mu \mathrm{m}$ per year $(0.05 \mu \mathrm{m}$ in 10 years).

The regressions for age versus vibration thresholds have also been compared with respect to VT and VPT. Judging from $r$ and $s_{y x}$, VPT showed a slightly better fit than VT to age but this was not significant.

\section{Discussion}

TECHNICAL CONSIDERATIONS

The discrimination power of the method presented for vibration threshold determinations is expressed by the variance ratio, $\mathrm{F}$, which was highly significant, and also highest, for the amplitude ( $\mathbf{A}_{\text {dig }}$ ) threshold measurements at all three stimulus sites compared to the voltage $\left(\mathrm{A}_{\mathrm{bio}}\right)$. The interindividual variation was also greater for amplitude than for voltage measurements, implying a better differentiation between subjects, regardless of age, for the amplitude parameter. The physiological data speak in favour of measuring the amplitude since deformation is the adequate stimulus to the receptors. Furthermore, different output of various vibrators (cf Fig. 3) necessitates measurement of the actual stimulator movement to permit comparisons. Such measurement also implies that the variable tissue damping effect is controlled. By filtering the accelerometer signal it is possible to eliminate the influence of environmental noise such as the tremor of the examinator's hand. The application pressure, which affects the vibration amplitude, can be controlled by a pressure indicator in the moving shaft of the vibrator (Johansson, in preparation). With such technical improvements, the measuring technique is standardised further, and the drawback of using a hand held vibrator (Dyck, 1975) is circumvented. The obvious advantage with such an instrument is that it is much more easily applied at various test sites and angles. In our experience, it is too time-consuming for clinical use to have a vibrator mounted on a stand. As regards the drive to the stimulator, manual dialling is preferred although it is less exact than an electronic switch that gives a controlled rate of change. Especially on patients with raised thresholds, it is convenient and timesaving to be able to adjust quickly the rate of rise and 
fall in stimulus strength to the particular threshold level.

\section{TYPE OF THRESHOLD}

The essence of the method of limits is to apply an ascending and a descending series of stimuli, and to take the average of the values where the sensation appears and disappears as the sensation threshold. We have so far been using this mean value (VT) routinely. An important result of the present statistical analysis is that the variance of the appearance or perception threshold (VPT) was less than that of the disappearance threshold (VDT). This suggests that it may be sufficient to determine only the VPT, at least when the threshold is normal. Patients with spinal or cerebral lesions, and possibly also those with peripheral nerve lesions, may display characteristic differences between VPT and VDT which would be overlooked if only the first value is recorded. The greater variance of VDT is compatible with the observation that several subjects find it difficult to determine when the vibration sensation disappears. This difficulty is more pronounced in some patients with raised thresholds.

\section{AGE RELATION}

It has long been known that the vibration sensitivity is age-dependent (see, for example, Pearson, 1928; Nielsen, 1972). This is important when separating normal and pathological thresholds for diagnostic purposes. We have found it practical to make tables for conversion of vibration amplitudes into standard deviations of age-related means.

The rise in threshold with age has usually been found to be logarithmic in the lower extremities (Rosenberg, 1958; Steinberg and Graber, 1963; Nielsen, 1972). This was confirmed in the present study for both tarsal and tibial stimulation. In the upper extremities, a rectilinear function gave a slightly better fit. A possible explanation may be that our older age groups, especially that of 50 to 59 years, were extraordinally "healthy" and, therefore, held down the expected rise in threshold, as is visualised in Fig. 4. Other explanations may be the shorter conduction distance to the central nervous system from the hand and the smaller range of carpal thresholds, which both may prevent the appearance of a logarithmic age-dependency. The question of the anatomical and physiological basis of the agedependency was not within the scope of this investigation and does not seem to be elucidated by our data.

\section{APPLICATIONS}

The most general application of vibrometry is to exclude or confirm impairment of vibratory sensi- tivity when the result of the tuning fork test is ambiguous. In polyneuropathies or central nervous system lesions, normal and pathological states can be separated by means of stimulation at the three standard sites for which reference values have been given. An extended control population which includes female subjects is in preparation. Vibrometry is also possible at sites for which reference values are missing, such as finger tips or toes, but comparison will then have to be made with the thresholds of homologous unaffected sites, for instance contralaterally. Circumscribed cutaneous nerve lesions are not suitable for the present vibrometry technique because of stimulus spread to deep or adjacent, normally innervated, tissues. For the same reason, vibrometry is not applicable on the head or thorax, except when sharp borders are searched in cases of hysterical hypoaesthesia.

Vibration threshold determinations have long been used to quantify reduced vibration sensitivity in spinal cord and peripheral nerve lesions, as well as for the early diagnosis of subclinical neuropathies. In a recent investigation of workers who had been exposed to jet fuel, the vibration threshold was the only neurological parameter which was significantly abnormal (Lindblom and Goldberg, 1979). Preliminary results in patients with polyneuropathy also $\frac{?}{\mathbb{Q}}-$ suggest that impairment of the vibration sense is a $\mathrm{c}$ sensitive index of certain types of nerve lesion, and that threshold measurements can be recommended in screening examinations for metabolic-nutritional or environmental neurotoxic effects, as a comple-ê ment to conventional neurological and neuro-? physiological methods. The reproducibility of the method encourages longitudinal studies by repeated measurements in the same patients using the vibration threshold as an index of the course of the disease and of therapeutic effects, as has been made in for instance uraemia (Bergström et al., 1975; Daniel et al., 1977), median nerve lesions (Neilson et al., 1969), and schizophrenia (Detre et al., 1962). A standardised vibrometry technique like the one described here can also be used in research investigations of the effects of therapeutic procedures (Lindblom and Meyerson, 1975; Verrillo and Eeker, 1977).

The study was supported by the research funds of the Karolinska Institute, Magnus Bergvall's foundation, and the Swedish National Board of Occupational Safety and Health. We are indebted to the late Sigge Ottosson, electronic research engineer at the Departments of Neurology and Clinical Neurophysiology at Karolinska Sjukhuset, to Dr Leonard Goldberg for statistical advice, and to Mrs Berit Lindblom and Mrs Ragnhild Knutsson for technical assistance. 


\section{References}

Bergström, J., Lindblom, U., and Norée, L.-O. (1975). Preservation of peripheral nerve function in severe uremia during treatment with low protein high calorie diet and surplus of essential amino acids. Acta Neurologica Scandinavica, 51, 99-109.

Calne, D. B., and Pallis, C. A. (1966). Vibratory sense: a critical review. Brain, 89, 723-746.

Cohen, L. H., and Lindley, S. B. (1938). Studies in vibratory sensibility. American Journal of Psychology, 51, 44-63.

Collens, W. S., Zilinsky, J. D., and Boas, L. C. (1946). Impaired vibratory sense in diabetes. American Journal of Medicine, 1, 638-641.

Cosh, J. A. (1953). Studies on the nature of vibration sense. Clinical Science (London), 12, 131-151.

Daniel, C. R., Bower, J. D., Pearson, J. E., and Holbert, R. D. (1977). Vibrometry and uremic peripheral neuropathy. Southern Medical Journal, 70, 1311-1316.

Detre, T. P., Feldman, R. G., Rosner, B., and Ferriter, C. (1962). Vibration perception in normal and schizophrenic subjects. Journal of Neuropsychiatry, 3, $145-150$

Dyck, P. J. (1975). Quantitation of cutaneous sensation in man. In Peripheral Neuropathy, pp. 465-479. W. B. Saunders Company: Philadelphia.

Egger, M. M. (1899). De la sensibilité osseuse. Journal de Physiologie et de Pathologie Général, 1, 511-520.

Fox, J. C., and Klemperer, W. W. (1942). Vibratory sensibility: A quantitative study of its thresholds in nervous disorders. Archives of Neurology and Psychiatry (Chicago), 48, 622-645.

Geldard, F. A. and von Haller Gilmer, B. (1934). A method for investigating the sensitivity of the skin to mechanical vibration. Journal of General Psychology, 11, 301-309.

Gregg, E. C. (1951). Absolute measurement of the vibratory threshold. Archives of Neurology and Psychiatry (Chicago), 66, 403-411.

Hunt, C. C. (1961). On the nature of vibration receptors in the hind limb of the cat. Journal of Physiology (London), 155, 175-186.

Knudsen, V. O. (1928). "Hearing" with the sense of touch. Journal of General Psychology, 1, 320-352.

Lindblom, U., and Goldberg, J. M. (1979). Screening for neurological symptoms and signs after exposure to jet fuel. Acta Neurologica Scandinavica, 60, suppl. 73, 64 .

Lindblom, U., and Lindström, B. (1976). Tactile thresholds of normal and blind subjects on stimulation of finger pads with short mechanical pulses of variable amplitude. In Sensory Functions of the Skin, pp. 105112. Edited by Y. Zotterman. Pergamon Press: Oxford.

Lindblom, U., and Lund, L. (1966). The discharge from vibration-sensitive receptors in the monkey foot. Experimental Neurology, 15, 401-417.
Lindblom, U., and Meyerson, B. A. (1975). Influence on touch, vibration and cutaneous pain of dorsal column stimulation in man. Pain, 1, 257-270.

Neilson, J. M. M., Boardman, A. K., McQuillan, W. M., Smith, D. N., Hay, R. L., and Anthony, J. K. F. (1969). Measurement of vibro-tactile threshold in peripheral nerve injury. Lancet, 2, 669-671.

Nielsen, V. K. (1971). The peripheral nerve function in chronic renal failure. I. Clinical symptoms and signs. Acta Medica Scandinavica, 190, 105-111.

Nielsen, V. K. (1972). The peripheral nerve function in chronic renal failure. IV. An analysis of the vibratory perception threshold. Acta Medica Scandinavica, 191, 287-296.

Nielsen, V. K. (1975). The vibration stimulus. Effects of viscous-elastic resistance of skin on the amplitude of vibrations. Electroencephalography and Clinical Neurophysiology, 38, 647-652.

Pearson, G. H. J. (1928). Effect of age on vibratory sensibility. Archives of Neurology and Psychiatry (Chicago), 20, 482-496.

Rosenberg, G. (1958). Effect of age on peripheral vibratory perception. Journal of the American Geriatrics Society, 6, 471-481.

Rumpf, H. T. M. (1889). Über einen Fall von Syringomyelie nebst Beiträgen zur Untersuchung der Sensibilität. Neurologisches Zentralblatt, 8, 222-230.

Rydel, A. and Seiffer, W. (1903). Untersuchungen über das Vibrationsgefühl oder die sog. "Knochensensibilität" (Pallästhesie). Archiv für Psychiatrie und Nervenkrankenheiten, 37, 488-536.

Sato, M. (1961). Response of Pacinian corpuscles to sinusoidal vibration. Journal of Physiology (London), 159, 391-409.

Sherrick, C. E. (1975). The art of tactile communication. American Psychologist, 30, 354-360.

Steinberg, F. U., and Graber, A. L. (1963). The effect of age and peripheral circulation on the perception of vibration. Archives of Physical Medicine and $R e$ habilitation, 44, 645-650.

Talbot, W. H., Darian-Smith, I., Kornhuber, H. H., and Mountcastle, V. B. (1968). The sense of fluttervibration: comparison of the human capacity with response patterns mechanoreceptive afferents from the monkey hand. Journal of Neurophysiology, 31, 301-334.

Treitel, L. (1897). Über das Vibrationsgefühl der Haut. Archiv für Psychiatrie und Nervenkrankenheiten, 29, 633-640.

Verrillo, R. T. (1966). Effect of spatial parameters on the vibrotactile threshold. Journal of Experimental Psycho$\log y, 71,570-575$.

Verrillo, R. T., and Ecker, A. D. (1977). Effects of root or nerve destruction on vibrotactile sensitivity in trigeminal neuralgia. Pain, 3, 239-255.

Williamson, R. T. (1922). The vibrating sensation in diseases of the nervous system. American Journal of Medical Sciences, 164, 715-727. 